\section{RETROPERITONEAL CYSTS}

\section{DEVELOPING FROM THE WOLFFIAN BODY-PARAPAN- CREATIC CYSTS.* \\ FRANCIS D. DONOGHUE, M.D. BOS'ToN.}

The results of frequent surgical intervention in the upper abdomen has gradually changed our ideas regarding tumors and their development in this region. This change in our ideas is analogous to that which followed frequent operations on appendiceal and pelvic conditions.

In spite of frequent operations, cystic tumors developing in the region of the pancreas and having relationship with, rather than belonging to, that organ are still denominated pancreatic cysts.

That fetal remains may be found retroperitoneally is a well-known and accepted fact. That tumors develop from the middle and lower portion of the Wolffian body and tubules, as well as from the ducts of Müller, is also well known. In view of this knowledge, it seems strange that for such a long time retroperitoneal cysts, other than dermoid, have usually been designated by the name of the glandular structure with which they were most intimately in connection. The uncertainty that exists in the identification of embryologic remains, especiallv in cysts in which the lining cells may have undergone marked change from atrophy and fluid pressure, makes it necessary to depend for diagnosis on the anatomic position of a cyst rather than on mere microscopic examination of the wall. Another important diagnostic point is their resemblance to other growths.

To trace briefly the development of the Wolffian body will enable us better to understand the growth of tumors derived from its remains.

First, in the embryology of vertebrates, we have, as the primitive constituents of the urogenital system on each side, four parts: 1 , the genital ridge; 2 , the Wolffian ridge; 3 , the Wolffian duct; 4 , the Müllerian duct. Out of the Wolffian ridge there arise three primary organs: (a) The pronephros (head kidney), with its excretory duct, the Wolffian duct; (b) its place is taken by the mesonephros (Wolffian body), an amniote or primitive kidney; (c) both are replaced by the true kidney.

The Wolffian body develops on the side of the vertebræ and retroperitoneally. ${ }^{1}$ Medially, it borders on the aorta and posteriorly on the posterior body wall. The Wolffian body extends down into the pelvis, its upper end extends up to the region of the liver and is united, together with the Wolffian duct, to the diaphragm. On the development of the kidney the Wolffian body retrogrades and the kidney finally develops in the position which it previously occupied.

The upper or sexual part (epoöphoron) is usually retained, and in the late fetal period suffers little change of location. The middle or sexual series of the Wolffian tubules, with the adjacent part of the Wolffian duct, becomes, in the female, an atrophic structure, known as the epoöphoron or parovarium, or organ of Rosenmüller.

The Wolffian tubules and the Wolffian body become, in the male, the system of excretory ducts of the testicle. ${ }^{2}$

The Wolffian body being situated in the tissue which furnishes the mesodermal elements of the mesentery, omentum and ether abdominal organs, these structures are able to carry with them in their changes of location

* Read in the Section on Obstetrics and Diseases of Women of the American Medical Assoclation, at the Fifty-seventh Annual Session, June, 1906.

1. Abel-Bandler: Gyn. Path., N. Y., 1901.

2. Heiser : Text-Book, "Fmbryology." ectodermal cells, from which normally develop ovary, epidermis, hair, nails, entire nervous system, spinal ganglia; and mesodermal cells, from which normally develop peritoneum, smooth muscle fibers, fibrous connective tissue, cartilage, bone, blood, blood vessels, etc. Later these may produce structures resembling those which they were destined to form had they remained in their normal situation.

Inasmuch as the first surgical interference was devoted to the lower abdomen, every movable cyst of the abdominal cavity was diagnosticated and operated on as ovarian for many years, practically up to 1898 . Later in the cycle of abdominal surgery, laterally placed cysts were considered nephritic, adrenal or splenic, and finally all the cysts of the upper abdomen were considered pancreatic, although the evidence of such origin has been, in most cases, of the very slightest.

In reporting a case which he called "multilocular cystoma of the pancreas, although no definite pancreatic tissue could be made out," Fitz ${ }^{3}$ quotes as "cysts of the pancreas" several cases in which the evidence making a diagnosis of pancreatic cyst would be possible is conspicuous by its absence. They are as follows:

CiberT's ${ }^{\star}$ CASE.-This was a case of cystic tumor in the upper abdomen removed by Poncet from a woman, aged 26. The growth was first noticed six years before operation, and it increased slowly for four years. Just before operation, it was apparently the size of the head of an adult. The cyst, when removed, was found to have a wall in which smaller cysts, no larger than hazel nuts, were found. They were lined with cylindrical epithelium and the wall of the main cyst was traversed by ridges enclosing communicating space.

Bozeman's ${ }^{5}$ CASE.-This case showed a principal cyst holding two and one-half gallons of brown fluid, the wall was trabeculated and bore several secondary cysts, the size of hen's eggs. The walls were lined with cylindrical or polygonal epithelium and hardened section showed that the formation of the secondary cysts took place as in an ovarian cyst.

RiEdel's ${ }^{\circ}$ CASE.- - This case occurred in a woman who died in four days after the puncture of the cyst. The cyst had an adenoid projection from wall. Several globular spaces were found communicating directly with the interior, the space being lined with cylindrical epithelium, and others had papillary elevations as in ovarian cystoma.

MARTIN's ' CASE.-A woman, aged 50, had a cyst removed from the region of the pancreas. It was so large it filled the entire abdomen. Sixteen years before she expected labor. The cyst was found behind the transverse colon. The cyst was isolated, except at one end, and cut away. A portion of the wall contained a large number of cysts, varying in size from that of a hazel nut to a goose egg. All were lined with cylin drical epithelium, and no pancreatic tissue was found.

RANSOHOFF's ${ }^{8}$ CASES.-Ransohoff reports 159 cases of pancreatic cyst subjected to operation. Seventeen were of the type of cyst adenoma. Of the 159, all but thirty-four were sewed to the abdominal wall and drained, with but five deaths. In twelve, operation could not be completed; four of these patients died; in twenty-three there was total enucleation, with two deaths. There have been about thirty similar cases reported since.

The report of his second case follows the conventional diag. nostic line. It was an epigastric tumor with resonance encircling it above and below. At the operation, the cyst was enucleated from its location and was found in such close relation to the pancreas that an examination of specimen showed a small piece of pancreas intimately incorporated with the ex. ternal surface of the tumor. The tumor was withdrawn between stomach and colon and the gastrocolic omentum divided.

3. Fitz: Am. Jour. Med. Scl., 1900.

4. Clbert: Gaz. des Hop., 1896

5. Bozeman : N. Y. Med. Rec., 1882.

6. Riedel : Arch. f. lilin. Chir., 1885.

7. Martin : Virch. Arch., 1890.

8. Mansohoff : Am. Med!clne, July, 1001. 
There was a thin, tough sac. Nowhere did there appear any infiltration of connective tissue with the epithelium. Completely healed in three weeks.

The following cases nave apparently been diagnosticated pancreatic from their relation rather than from the presence of pancreatic tissue. They answer to all the characteristics of Wolffian body cysts:

LoIILEIN's CASE.-The cyst extended back to the spine and down into the pelvis, compressing the ascending and transverse colon, and had a fibrous wall. The contents consisted of a thin, yellow, mucus-like fluid.

Obalinski's ${ }^{10}$ CAsE.-Obalinski described a retroperitoneal cyst with a wall composed of firm connective tissue and elas. tic tissue. There were liters of clear, watery fluid. He refers to an article by Petryowski, in which similar cases are reported, and the origin from the Wolffian body or Müllerian duct suggested.

CaRTeR's" CASE.-Carter cites a case of a thin-walled cyst attached to spine in left lumbar region.

Morris's' ${ }^{12}$ CASE.-This was a case of a woman who was delivered of a malformed fetus. She had at the time a tumor, in-

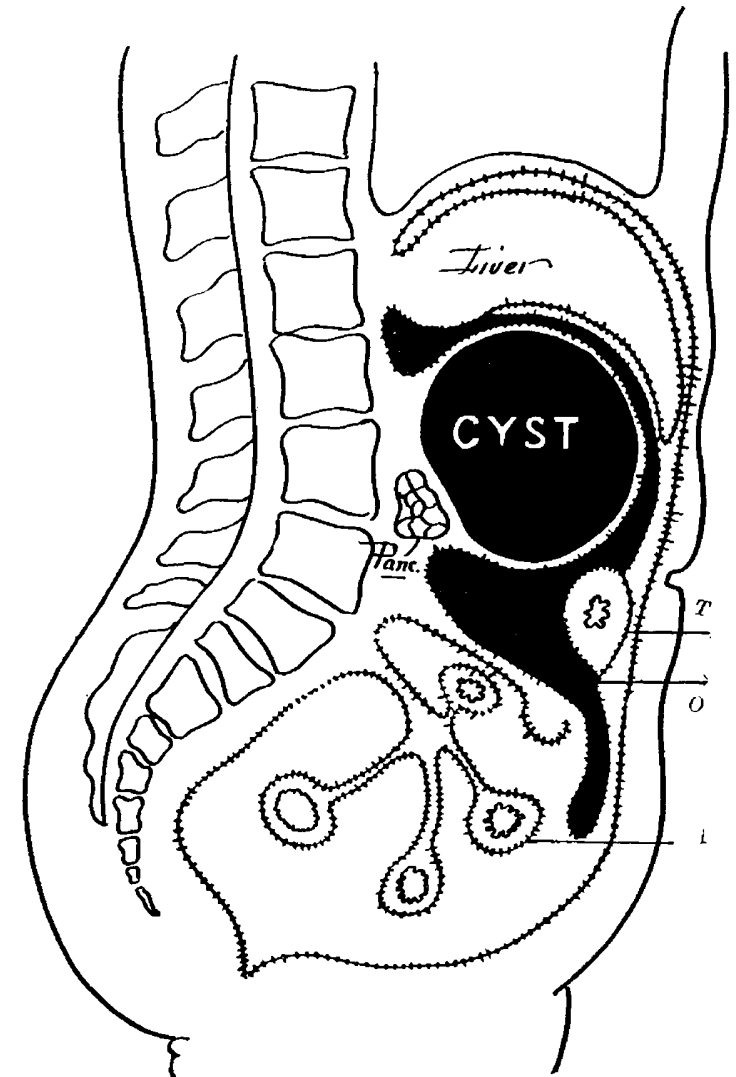

T. Transverse colon. 0 . Omental bursa. I. Intestine. The dashed line indicates the peritoneum.

dependent of the uterus, which was subsequently diagnosticated as a cyst of the pancreas. The cyst ruptured spontaneously into the intestine, effecting a cure of all symptoms.

PEAN's ${ }^{18}$ Cases.-This author made personal observation of three cystic tumors and found them all attached to the posterior wall of the abdomen. They appeared to have got between the layers of the omentum secondarily in the process of growth.

Pitchrond's" CAse.- "Alice P., aged 29, single, had noticed a tumor gradually increasing in size for past two years. There was little inconvenience from its size until about five weeks before operation. Her only complaint was of some increase in dyspepsia and pains in the abdomen and back.

9. Loblein : Berl. klin. Wochft., 1889.

10. Obalinsk 1 : Wlen. klin. Wochft., 1891.

11. Carter: Brit. Med. Jour., January, 1883.

12. Morrls: Lyon Medical, September, 1901.

13. I'esn: Bull. de la Soc. d'Anat., 1848.

14. F't therord: Trans. Path. Soc., London, 1903.
"Examination.-Examination showed tumor mesially placed and lying, for the most part, in the hypogastric region, about one-third only being in the epigastric region. The general contour was ovoid, the narrow end being upward; its size was about that of a cocoanut. It was freely movable upward and to the right, but less so to the left and downward. The tumor was dull on percussion all over; it was surrounded on all sides by a band of resonance. The urine was normal.

"Operation.-Operation showed uterus and appendages normal. The great omentum was found to be stretched out over the tumor. The transverse colon was found to be displaced downward by the tumor. The growth projected through that part of the great omentum which lies between the stomach and the transverse colon. It was also behind the parietal peritoneum of the lesser sac. The tumor was shelled out of its bed with comparative ease. The sides were found to be bound to the posterior abdominal wall by connective tissue. Incision closed without drainage and patient left hospital in sixteen days. The growth was of the nature of a multilocular eyst and had a common wall of tough connective tissue, the thickness varying from $2 \mathrm{~mm}$. to $6 \mathrm{~mm}$.

"Microscopic Examination.-This showed the main tissue of the cyst walls to consist of bundles of fibrous tissue packed in varying degrees of closeness. In the fibrous tissue were foci of more actively growing connective tissue. In some places these young connective tissue cells appear grouped in heaps below the lining epithelium; in this way are formed low eminences, projecting into the cavity of the cyst. In two of the sections typical gland tissue was encountered.

"Remarks.-This multilocular cyst tumor developed behind the peritoneal covering of the posterior wall of the lesser peritoneal cavity. There can, I think, be little doubt that it was derived from the pancreas, being developed, probably, very early in life in some outlying fragment or accessory portion of the gland.

"If this theory is correct, it is interesting to note that rancreatic properties were entirely absent from the cyst contents. The simplicity of construction and the absence from the tumor of cartilage, bone, striped muscle or skin organs preclude, I think, the suggestion of teratoma. More suggestive of a pancreatic origin than mere anatomic position are, however, the characters of the traces of glandular tissue found in the specimen."

Chartle's ${ }^{16}$ Case.-“A woman, aged 45, had a fixed cystic swelling, occupving the hypogastric and left iliac regions, but not involving the pelvis. There was resonance in front. Three years' history of growth. The cyst contained a fluid of brown color and tufts of papillomatous tissue could be seen microscopically. The wall of the cyst was covered by epithelium, arranged in a slightly papillomatous manner. The cyst was behind the sigmoid and between the layers of its mesocolon."

MCMURTRY's" CASE.-This case shows "a eyst, having its origin in the colonic mesentery on the left side, and when it had extended to the right it had grown at the expense of the wall of the tumor. It occupied the entire upper left quadrant of abdomen. It was a serosanguineous cyst of the mesentery, arising in the colonic mesentery near the left kidney. The sac, which was very thin, was enucleated."

Cartleder'si ${ }^{\text {in }}$ CAse.-A woman, aged 45, had a large, freely movable cyst in left side of abdomen, immediately under the rib. It could be pushed downward and simulated the location and feel of a cyst of the left uterine appendage. It had a thick wall and was enucleated. It weighed six pounds; the contents were like rich chocolate.

Cysts of the omentum and mesentery are more apt to be confounded with ovarian tumors than retroperitoneal cysts. These have been fully considered by Dowd, ${ }^{18}$ Ayer $^{19}$ and Porter. ${ }^{20}$ There is unanimity of belief that in this class of cases cysts develop from embryologic remains.

15. Chartle: Med. Press., March 1, 1905

16. MeMurtry : Lousisvile Mon. Jour., 1904-05

17. Cartledge: Trans. South. Surg. and Gyn. Soc., 1902.

18. Dowd : Annals of Surg., 1900.

19. Ayer: Amer. Jour. Med. Scl., Tanuary, 1906

20. Torter: Annals of Surg., March, 1906. 
The following cases reported as retroperitoneal cysts simulating cyst-adenoma of kidney or floating kidney also evidently developed from Wolffian body remains:

KRUSEN's" CASE.-This is a case of cyst of the kidney simulating ovarian cyst.

A woman, aged 34 , had a mass which had been growing for three years and was very movable. She had dragging pain, relieved by lying down. Urine was negative. Cyst was the size of an ordinary football, occupying the right side of the abdomen and having no connection with the uterine appendages. It was retroperitoneal and the walls were thin and tense. The Huid was clear and colorless.

"On examination it was found to be connected with the right kidney, which was considerably atrophied. It resembled a cyst of the right ovary with a long pedicle."

ELDER'S ${ }^{22}$ CASE.-A case of paranephritic cyst simulating a floating kidney.

A single woman, aged 30 , had a tumor which had developed some time in the past six years. During this time she had various attacks of pain in the right side of the abdomen, accompanied by nausea and vomiting. Examination showed a tumor the size and shape of a kidney, moving freely with respiration, and movable into the different quadrants of the abdomen. Urine was normal. Operation revealed a retroperitoneal cyst, independent of the kidney. The cyst was found to be divided into three loculi, which communicated with each other. The wall was composed of fine, fibrous connective tissue and enciosed a straw-colored fluid.

PAwLIK's ${ }^{23}$ CASE.-A woman, aged 43 , was supposed by Pawlik to be suffering from hydronephrosis, although urine was normal in quantity and quality. The operation showed pararenal cyst, unconnected with kidney.

The grouping by Dowd ${ }^{\mathbf{1 8}}$ of hydatid, chylous dermoid and other cysts of a similar nature under the head of embryologic tends to simplify our understanding of these tumors. As cystic tumors have been identified as originating in all parts of the Wolffian body tract, except the upper, a logical step would be to group under the head of retroperitoneal Wolffian body cysts all cysts of the upper abdomen in which development from glandular organs can not be conclusively demonstrated.

Lockwood's ${ }^{24}$ CASE.-Lockwood was the first clinician to suggest the real cause of the development of these cysts. He reports a case, with remarks.

The patient was a woman, aged 20 , in whom an operation disclosed a cyst as large as an ostrich's egg, behind the descending mesocolon. Urine was normal. The colon lay to its outer side, but had no connection with it. After the removal of the cyst, the ureter, which lay behind it, came into view. The cyst itself lay among loose connective tissue, back of the peritoneum. It was unilocular, and filled with a chocolatecolored, semi-fluid mass, consisting of fibrin, blood pigment, and cholesterin. Microscopic examination showed contents to be simply altered blood clots. No glandular structure was found.

In attempting to account for cysts, he says: "The suprarenal body may be developed from the Wolffian body, but, at all events, it is continuous with it until a late period of intra uterine life. At this period the lower end of the Wolffian body is already becoming converted into the epididymis and other structures about the testis; in the female it is becoming epiovarian or parovarian. Thus it is evident that between the suprarenal body and the ovary or testis, there is, along the course of the ureter, a part of the Wolffian body which has hitherto been unaccounted for. How long this persists or what may be its ultimate fate is unknown.

"Now it is so notorious that the part of the Wolffian body which is in relation to the ovary and testis is prone to give rise to various kinds of eysts, that it does not seem unreasonable to assume that the remaining part, viz., along the ureter,

21. Krusen : Am. Medicine, January, 1006

22. Hider: Montreal Med. Jour., 1905.

23. Pawlik: Arch. t. klin. Chir.. vol. liti. p. 571

24. Iockwood: Trans. Path. Soc., London. 1898. may do so likewise, and I venture to suggest this is the origin of the cyst which I have just described."

DUNNING'S ${ }^{23}$ Case.-A married woman, aged 25, had a lump in the left side, under short ribs and complained of occasional attacks of pain. The diagnosis was hydronephrosis. When at rest, the tumor oecupied a position just below the stomach.

Operation.-Operation revealed a large tumor, with dense, tibrous capsule. From main cyst, forty or fifty smaller cysts projected into and filled the main cavities. They were filled with slightly turbid, tenacious, mucoid material. "It is called a pancreatic cyst because it occupies the position usually occupied by such a cyst, and is attached to the pancreas."

Pathologic Report.- "While this adenomatous tissue is not typical of pancreatic tissue, it might pass for such. We have failed to demonstrate the presence of the two most positive signs of the pancreatic origin. It has, however, been the cus tom to classify cysts occupying a similar position and attached to the pancreas as pancreatic cysts."

In their work, page 202, Robson and Moynihan" state: "Unless a careful postmortem examination is made, the origin of the tumor of the pancreas can not be proved, for if the growth begins in the suprarenal capsule in adhesion to the pancreas, it is probably found very early on the left side, and at the operation a portion of the pancreas may have to be removed."

Dunning says: "In my case, I think the suprarenal capsule origin may be excluded, because when at rest, it was two or three inches removed from the site of the suprarenal gland and kidney. Neither could the case be described as a cyst of the omentum as it lay entirely behind the omentum."

Lloyd ${ }^{27}$ says: "Because the examining finger enters a cavity containing fluid behind stomach, at the bottom of which the pancreas is felt, there is no reason to call it cyst of the pancreas," and he suggests the term pancreatic pseudo-cysts for bursitis of the lesser peritoneal cavity with tumor formation. The method of formation of pseudo-cysts and the fact that they have no definite cellular wall structure suggests, as several writers have pointed out, that when the pancreas is injured there is an effusion of blood and pancreatic secretion in the lesser cavity of the peritoneum (or from gallstone disease some obstruction to foramen of Winslow may arise, especially if there is severe cholecystitis and gangrene) which seals (closes) the foramen of Winslow. The fluid continues to irritate, so that very soon the cavity is fully distended. This causes at first a rapid tumor formation, which afterward enlarges very slowly. This occurs below and behind stomach and large intestine.

As the fluid pours out into pre-existing space, the tumor takes the shape of lesser peritoneal cavity, being deepest above and toward the left in the direction of the spleen. The treatment really consists in incising through the thin peritoneal covering and stitching the walls of the cavity to the abdominal wall. "In these cases, the anterior wall which is incised is scarcely thicker than the normal gastrocolic omentum. ${ }^{28}$ The transverse mesocolon may be so thin as to allow leaking of fluid which causes general peritoneal symptoms.

CoOMBES AND NASH's ${ }^{20}$ RePoRT.-In connection with a report of a case of their own Coombes and Nash also report twenty-five cases which they call traumatic pancreatic cysts, in which there is effusion into the lesser peritoneal cavity. In this table, twenty-three occurred in males and two in females. Youngest male, two; oldest male, fifty-eight. One woman, aged 23, had suffered three years. The cause of the trouble was a fall from a great height.. ${ }^{30}$ The other woman, aged 20, had suffered one year. Cause of trouble was a blow on the chest by a swinging door. ${ }^{\text {s1 }}$

25. Dunning: Am. Jour. Obst., 1905.

26. Robson and Mopnihan: "Diseases of the Pancreas."

27. Iloyd : Brit. Med. Jour., 1892.

28. Blayney: Trans. Royal Acad. Med., Ireland, 1904

29. Cocimbes and Nash: Lancet, 1901

30. Relgner : Berl. klin. Wochft., 1890

31. Boyd : Clin. Jour., February, 1900. 
Twenty-nine cases, including eleven males and eighteen females, with an average of 36 , were non-traumatic. The seven cases in which they found that excision was attempted or performed, suggesting a definite wall, were all in females.

Rolleston's ${ }^{82}$ CASE.-This was a case of acute pancreatitis, which gave rise to a localized peritonitis, with effusion, occupying the lesser sac of the peritoneum. He remarks that, "It is noteworthy that this peripancreatic cyst resembled closely a true pancreatic cyst, both in its position and relations and in the chemical and digestive properties of its containing fluid. It is impossible to be certain whether a cyst in this situation is pancreatic or peripancreatic, merely from clinical examination, and diffcult, even if the case is operated on, unless a piece of the wall is removed and examined microscopically for the presence or absence of pancreatic tissue. A point which might be useful is the presence or absence of fat necrosis. Its presence would be strongly in favor of a peripancreatic cyst secondary to pancreatitis, since it does not seem to occur in true pancreatic cysts. What the relative frequency of peripancreatic effusions secondary to pancreatitis and of the pancreatic cysts really is, it is difficult to determine. Clinically, the term pancreatic cysts is used to cover both."

If it is reasonable to believe the theories advanced as to the formation of pseudo-cysts, it is also reasonable to believe that pressure from a tumor developing under the postparietal peritoneum may lead gradually to the changes in the pancreas which it is claimed are set up by direct and sudden violence.

\section{AUTHOR'S CASES.}

The conclusions arrived at in this paper are based on a consideration of reported cases and on three cases of cystic tumor developing in the epigastrium which have been under my charge. Two of these cases I saw while acting as an assistant to Dr. S. J. Mixter. Both of these cysts had a definite wall and appeared between stomach and transverse colon and were treated by enucleation. The third case, which I report in full, was under $m$ ! charge last year.

Patient.-Mrs. S., married, aged 45, was born in Massachusetts and had had no previous illness, except measles when a child.

History.-Her father was alive, aged 88. Mother died of pneumonia at 54 . Two sisters died during infancy. One brother died at 49 of Bright's disease. Three brothers and one sister are alive. She was married at 19 , and has two daughters, ages 25 and 27 . She has had no trouble during pregnancy or during delivery and no miscarriages.

Catamenia was always regular and painless up to May, 1904, when she was unwell six weeks in succession. She has been unwell only once since. Ten years ago, while taking some wood from one house to another, she slipped on the stairs, and thought at the time she had a strain, but this apparently got well, as she made no further complaint. During the latter part of the summer of 1904, she had "stomach trouble." She had nausea and distress after eating.

She was examined carefully by a physician, who found nothing to suggest anything other than indigestion. Stomach trouble continued, with gradual loss of flesh, amounting in all to about thirty pounds. On getting up in the morning she always felt fine, but as the day went on nausea increased. She was troubled with nausea in the morning after breakfast and vomiting after dinner and supper.

In September, 1904, she noticed a bunch in the abdomen for the first time. It was movable from the right side to the median line, along the lower costal border.

Some time after this she tripped and fell, and following this, there was a constant increase in the size of the swelling. At Christmas she was confined to her bed for two or three days on account of severe indigestion. She was also slightly jaundiced at this time. Her bowels were constipated and she found that the less she ate the better she felt. Her com-

32. R.Jlleston: Trans. Path. Soc., Lonđon, 1898. plexion became sallow and yellowness of eyes persisted for some time. The urine was normal in quantity and constituents. The constant growth of the tumor caused her to call Dr. J. A. Magee, of Lawrence, in February, 1905, and a few days after his first visit, $I$ saw her in consultation on February 8.

Examination.-The story of the case was related as above, and examination showed a pale, poorly-nourished woman, who showed the effects of a marked loss in flesh. Examination of heart, lungs and pelvic organs was negative. There was no edema of extremities. Abdominal walls were very Iax. In the upper left abdomen, in the region of the gall bladder, was a tense, fluctuating tumor. It was as large as a man's head, and moved with respiration. It was movable in all directions, but most so toward and beyond the median line to the left. There was dulness above and to the outer side, with resonance below and to the left. As the woman changed her position in the bed, the tumor changed its position. But, as she lay on her left side, the zone of movement seemed toward the left and up toward the ensiform cartilage.

Diagnosis.-The diagnosis rested between a cyst of the gall bladder, pancreas, mesentery, or a hydronephrosis.

operation.-Operation was advised, and was performed on Feb. 14, 1905, at the Elliot Hospital. In the operation I was assisted by Dr. Magee and Dr. Emil Ruppel, of Lynn.

Incision extending from opposite the end of the ninth rib to a point just below the umbilicus, was made through the right rectus muscle. When the peritoneum was incised, a large, glistening cyst of the same apparent nature and appearance as a parovarian, was seen. The liver was pulled down in a thin, broad band over the upper portion of the tumor. The gall bladder was to its outer side and behind. There was no area or evidence of fat necrosis. The stomach was just visible at left end. An incision was made through the peritoneal attachment to the liver and the cyst was shelled out in a similar manner to the enucleation of a gall bladder in cholecystectomy.

The cyst was found covered by two layers of peritoneum and on turning cyst up and going through the gastrohepatic omentum, the cyst which had a fairly firm fibrous wall was enucleated back to the top of the panereas, which could be felt. One or two large blood vessels, which made something of a pedicle, were ligated and the cyst removed entire.

During the operation an occasional large blood vessel was tied.

After the enucleation, the cavity from which the cyst came was practically devoid of fluid or bleeding. The abdomen was closed without drainage, and the patient made an uneventful recovery, going home on the sixteenth day. The stomach symptoms disappeared after the third day and have not returned.

Postoperative History.-In the year following the operation, her complexion cleared up and she has regained her original weight. I saw her the first of May of this year and she is entirely well. She has not had an unfavorable symptom since leaving the hospital.

Microscopic Examination.-Dr. W. F. Whitney of the Harvard Medical School reports the specimen to be "similar to the ones removed by Dr. Mixter, being a thin-walled cyst, presumably from remains of the Wolffian body and resembling a parovarian cyst."

Dr. W. P. Graves, of the Free Hospital for Women, made a further examination and reports as follows:

"Wall is made up of pure fibrous tissue which contains areas of round-cell infiltration. There are also areas of large palelystaining cells which are apparently collections of endothelial cells. Scattered through the fibrous tissue are smooth muscle fibers. The wall is vascular and contains numerous capillary blood vessels which have a thick, prominent, endothelial lining. The interior surface of the cyst is lined by epithelium. In places this epithelium consists only of a single cuboidal layer. In other places the epithelium is heaped up in cuboidal or polygonal forms. In still other places the epithelium at the surface has a distinct tubular formation. Beneath the epithelial lining is a well-marked zone of cytogenous tissue and this structure together with the occasional appearance of tubular epithelium gives a suggestive glandular appearance. In 
no instances could the epithelium be found to be ciliated. Diagnosis : Retroperitoneal cyst."

SUMMARY OF DIAGNOSTIC POINTS.

To summarize some of the diagnostic points :

A cyst developing from Wolffian body remains develops back of the retroperitoneum and may push the stomach in any direction or may develop behind and push forward the aorta and vena cava.

True cysts of the pancreas would not be likely to do this on account of its relations.

The greater the amount of substance secreted and the greater the amount and the number of products from the displaced ectodermal or mesodermal cells the larger the cyst.

Lateral mobility has been considered diagnostic of mesenteric cysts, but mobility is also characteristic of most tumors of the upper abdomen, which do not develop directly from a glandular organ.

"A ferment which converted starch into sugar has been found absent from undoubted pancreatic cysts,"26 "and has been found in abdominal cysts not connected with the pancreas." ${ }^{33}$

Slowly developing obstruction to the pancreatic duct or from interstitial changes may cause cystic degeneration of that organ.

Pancreatic cysts are finely fixed and do not attain large size. ${ }^{\mathbf{3 4}}$

It may be considered that there have been, under the head of pancreatic cysts, three forms described: 1 . The small, true, firmly fixed cyst of the pancreas, which is accompanied by glandular destruction, and rarely presents as a tumor in the living. 2. The thin-walled, friable pseudo-cysts which are full of pigmented material. Fifforts to remove these have been generally unsuccessful, so they have been treated by drainage. They present below stomach, with areas of tympany above and below. 3. A thin, fibrous-walled cyst of large size, containing, as a rule, cholesterin fluid; freely movable, and can be enucleated ; resembles closely a parovarian cyst and develops in close relationship to the pancreas. The first are true pancreatic cysts; the second, pseudo-cysts or omental bursitis; the third are Wolffian body cysts, and stand in the same relation to the pancreas as do parovarian cysts to the ovary; or if another descriptive name is needed, these might be called parapancreatic cysts.

Aspiration should never be performed on account of clanger of infection, either from puncture of some hollow viscus, or from disseminating cyst contents.

\section{CONCLUSIONS.}

The clinical picture of a cyst developing behind the peritoneum, from embryologic remains, depends on the relations it finally assumes.

Cysts from the Wolftian body are not uncommon in women.

Movable cysts presenting in the epigastrium have usually been called pancreatic, although true cysts of the pancreas are rare (especially in women) and are rarely movable.

Developing in the region of the kidney, they may be mistaken for hydronephrosis or may extend so low as to be considered ovarian.

Retroperitoneal cysts are usually benign, unaccompanied by symptoms other than those of a mechanical nature.

409 Marlborough Street.

\footnotetext{
33. Morton : Brit. Med. Jour., 1903.
}

34. Douglass: Trans. Soutb. Surg. and Gyn. Soc., 1902.
TETANUS NEONATORUM.

A SECOND REPORT OF A STATISTICAL STUDY. $\dagger$

JAMES M. ANDERS, M.D., LL.D.

AND

ARTHUR C. MORGAN, M.D.

PHILADELPHIA.

A second paper on the study of the incidence of tetanus in the United States is herewith presented. Special attention has been given to the subject of tetanus neonatorum, and the literature from 1850 to 1906 (covering reports of cases found in the "Index-Catalogue of the Library of the Surgeon-General" in Washington from 1850 to 1892 , and in the Index Medicus from 1892 to 1906 inclusive), has furnished 1,276 cases. with a report of 31 original ones, collected by us from direct correspondence with hundreds of observers all over the TABLE 1.-MOR'TALITY OF TETANUS IN CENSUS YEARS AS SHOWN BY U. S. VITAL STATISTICS.

\begin{tabular}{|c|c|c|c|c|c|c|c|c|}
\hline & \multicolumn{2}{|c|}{1870.} & \multicolumn{2}{|c|}{1880.} & \multicolumn{2}{|c|}{1890.} & \multicolumn{2}{|c|}{1900.} \\
\hline & 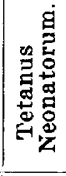 & 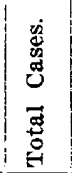 & 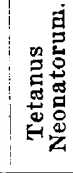 & 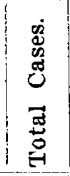 & 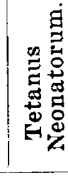 & 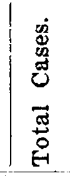 & 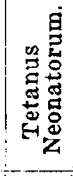 & 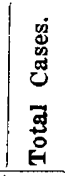 \\
\hline $\mathrm{ma}$ & 28 & 52 & 86 & 108 & 9 & 96 & 3 & \\
\hline & & & & & & & & \\
\hline ifa & & $\begin{array}{r}8 \\
19\end{array}$ & 16 & $\begin{array}{l}25 \\
11\end{array}$ & $\begin{array}{l}7 \\
9\end{array}$ & $\begin{array}{l}15 \\
29\end{array}$ & $\begin{array}{l}1 \\
7\end{array}$ & \\
\hline : & & 1 & 1 & 2 & 2 & 6 & & \\
\hline icut & 1 & 9 & 3 & 20 & $1 \overline{3}$ & 18 & 9 & \\
\hline & & & $\cdots$ & $\cdots 1$ & & $\cdots \cdots$ & & \\
\hline et of Columbia. & 2 & $\begin{array}{l}3 \\
6\end{array}$ & 9 & 13 & 52 & $\begin{array}{r}7 \\
58\end{array}$ & 9 & \\
\hline la $\ldots \ldots \ldots$ & 4 & 11 & 26 & 35 & 27 & 33 & 26 & \\
\hline la $\ldots$. & 16 & 27 & 38 & 60 & 42 & 62 & 19 & \\
\hline . & & & 01 & & & & & \\
\hline$\because$ & $\begin{array}{l}5 \\
4\end{array}$ & 26 & 24 & 63 & 63 & 100 & $\begin{array}{l}36 \\
11\end{array}$ & 12 \\
\hline$\ldots$ & 4 & 13 & 17 & $\begin{array}{l}40 \\
13\end{array}$ & $\begin{array}{l}10 \\
10\end{array}$ & 1 & 11 & \\
\hline is $\quad \ldots$ & 2 & 2 & 3 & 9 & 4 & 1 & $\ddot{3}$ & 2 \\
\hline ky . & 14 & $3 \overline{6}$ & 21 & 51 & 49 & 64 & 11 & 4 \\
\hline$\cdots$ & 374 & 507 & 149 & 178 & 268 & 299 & 106 & 29 \\
\hline$\cdots$ & & 07 & & & & 6 & & \\
\hline & 14 & 31 & 15 & 24 & 36 & 46 & 16 & \\
\hline isetts $\ldots \ldots$ & 2 & 18 & 7 & 17 & 6 & 9 & 3 & \\
\hline$\cdots \cdots$ & 1. & 6 & $\mathbf{3}$ & 8 & 13 & 31 & 7 & 3 \\
\hline ta $\ldots \ldots$ & 1 & 3 & 8 & 12 & 7 & 15 & 2 & \\
\hline pi & 34 & 48 & 47 & 61 & 19 & 29 & 2 & 2 \\
\hline rerritory & & $\cdots$ & $\cdots$ & $\cdots \cdots$ & $\cdots$ & $\cdots$ & $\because$ & \\
\hline MIs & 88 & 166 & 33 & 59 & 180 & 200 & 57 & 10 \\
\hline$\ldots \ldots$ & 1 & 1 & $\cdots$ & 4 & & 6 & 3 & 1 \\
\hline & & & & & & & & \\
\hline Hampshire & & 1 & & 8 & & 1 & & \\
\hline New Jersey . & 6 & 19 & 16 & 35 & 68 & 80 & 38 & 9 \\
\hline New Mexico & & 1) & & 3 & & 2 & & \\
\hline New York & 58 & 112 & 14 & 50 & 99 & $14 \overline{6}$ & 57 & 20 \\
\hline North Carolina & 7 & 13 & 39 & 54 & 12 & 18 & 8 & 4 \\
\hline h Dakota. & & 10) 20 & 10 & & & $\pi 1$ & 1 & \\
\hline$\ldots \ldots \ldots$ & 7 & 40 & 10 & 43 & 45 & 77 & 10 & 8 \\
\hline : & &. & $\cdots$ & $\cdots \dot{2}$ & $\because$ & $\dot{1}$ & & $\cdots$ \\
\hline Ivania & & $6 \dot{0}$ & $2 \dot{1}$ & 70 & 35 & 74 & $\dot{2 i}$ & 16 \\
\hline hode Island & & 3 & 3 & 6 & & 5 & 2 & \\
\hline Carolina & 29 & 42 & 26 & 31 & 106 & 114 & 67 & $\theta$ \\
\hline Dakota & & & & & 3 & 3 & $\ldots$ & \\
\hline essee $\ldots$ & 25 & 46 & 52 & 84 & 35 & 0 & 6 & 4 \\
\hline$\ldots \ldots$ & 183 & 212 & 212 & 256 & 126 & 157 & 11 & 13 \\
\hline$\because \cdots$ & 1 & $\because$ & $\because$ & $\because 1$ & $\cdots$ & 1 & 1 & \\
\hline ont & 1 & & 1 & 3 & & & & \\
\hline . & 43 & 65 & 43 & 61 & 47 & 65 & 15 & 6 \\
\hline & $\cdots$ & $\cdots$ & & & $\cdots$ & $\cdots$ & $\cdots$ & \\
\hline irginta & & & f & 7 & 4 & 9 & & \\
\hline in $\quad \ldots$. & 1 & & 6 & 10 & 12 & 21 & 7 & 28 \\
\hline yoming ${ }_{\text {Largest }}$ cities $\ldots$ & $\because$ & $\cdot$ & 762 & $\dot{9} \dot{\mathbf{5}}$ & $\cdots$ & $\cdots$ & $\cdots \cdots$ & $\cdots$ \\
\hline Total & 975 & 627 & 716 & 2537 & 1491 & 2019 & 595 & 2259 \\
\hline
\end{tabular}

t Read in the Section on Diseases of Children of the American Medical Association at the Fifty-seventh Annual Sesstion, June, 1906.

* The figures for 1900 are furnished by the Bureau of the Census, Division of Vital Statistics, Washington, and are incomplete for the non-registration states, which are Alabama, Arizona, Arkansas, California. Colorado, Delaware, Florida, Georgla, Idaho, Illınois, Indian Territory, Indlana, Iowa, Kansas, Kentucky, Louisiana. Maryland, Minnesota, Mississippl, Missourl, Montana, Nebraska, Nevada, New Mexico, North Carolina, North Dakota, Ohlo, Oklahoma, Oregon, Pennsylvania, South Carolina, South Dakota, Ternessee, Texas, Utah, Virginia, Washington, West Virginla, Wisconsin and Wyoming. 